\title{
Trends in Psychiatric Hospitalization of Children and Adolescents in Spain between 2005 and 2015
}

\author{
Carlos Llanes-Álvarez ${ }^{1, * \mathbb{0}}$, Jesús M. Andrés-de Llano ${ }^{2}$, Ana I. Álvarez-Navares ${ }^{3}$, \\ M. Teresa Pastor-Hidalgo ${ }^{4}\left(\mathbb{D}\right.$, Carlos Roncero $^{3}{ }^{-1}$ and Manuel A. Franco-Martín ${ }^{1}$ (B) \\ 1 Department of Psychiatry, Complejo Asistencial de Zamora, 49022 Zamora, Spain; \\ mfrancom@saludcastillayleon.es \\ 2 Department of Pediatrics, Complejo Asistencial Universitario de Palencia, 34005 Palencia, Spain; \\ jm.andres.dellano@gmail.com \\ 3 Department of Psychiatry, University of Salamanca Health Care Complex, 37007 Salamanca, Spain; \\ aialvarez@saludcastillayleon.es (A.I.Á.-N.); croncero@saludcastillayleon.es (C.R.) \\ 4 Castilla y León Health Authority, Complejo Asistencial de Zamora, 49022 Zamora, Spain; \\ mtpastor@saludcastillayleon.es \\ * Correspondence: cllanes@saludcastillayleon.es; Tel.: +34-980-548-820 (ext. 48200)
}

Received: 19 October 2019; Accepted: 26 November 2019; Published: 2 December 2019

\begin{abstract}
Eating disorders are on top of chronic conditions in children and adolescents, and the most severe cases may require hospitalization. Inpatient psychiatric treatment is one of the most expensive ones and therefore the efforts when treating eating disorders should focus on avoiding and shortening admissions, as well as preventing readmissions. Advances in of eating disorders treatment lie in an accurate knowledge of those patients requiring admission. This study examined the Conjunto Mínimo Básico de Datos—the largest public hospitalization database in Spain—to estimate the prevalence of eating and other psychiatric disorders during childhood and adolescence. It is a cross-sectional study of the hospital discharges in Castilla y León (Spain) from 2005 to 2015, in which patients under 18 years old with a psychiatric diagnosis at discharge were selected. Trends in the rates of hospitalization/1000 hospitalizations per year were studied by joinpoint regression analysis. Conclusions: eating disorders were the only group that presented an upward and continuous trend throughout the study period. This statistically significant increase showed an annual change of $7.8 \%$.
\end{abstract}

Keywords: child psychiatry; eating disorders; big data; hospitalization; decision making; organizational

\section{Introduction}

Childhood and adolescence are high-risk stages for the onset of mental disorders [1,2]. Such disorders and associated problems can make it difficult to acquire developmental milestones and successfully transition children and/or adolescents into adulthood [3,4]. Numerous epidemiological studies have investigated the prevalence of mental disorders in childhood and adolescence, showing that they are relatively frequent among children and adolescents. Their prevalence from childhood to 18 years old is around $25 \%-30 \%[5,6]$.

Hospital care in children and adolescents has proven to be effective $[7,8]$ and continues to be necessary for the comprehensive assistance of children and adolescents. Even so, there are few studies that analyze hospitalization due to psychiatric causes among patients under 18 years of age. The study of trends in psychiatric hospitalization in children and adolescents has not been a priority because these patients represent only around 7\% of the total population of hospitalized psychiatric patients [9]. Inpatient psychiatric treatment is one of the most expensive ones, and it is estimated that it represents almost half the annual cost of mental health treatment for children and adolescents [10]. However, and 
despite the efforts to develop outpatient alternatives, there are cases in which hospitalization is still necessary [11].

Eating disorders have become one of the most common chronic diseases in the pediatric age group, especially among females, and they almost exclusively afflict young persons. The peak ages for these diseases are late adolescence and young adulthood, in both cases under 18 years old. The incidence of eating disorders appears stable overall but may be increasing in younger age groups. Previous studies have demonstrated that the representativeness of the available eating disorder prevalence data is poor [12,13]. In Spain, data on incidence and clinical features of eating disorders are sparse too.

For epidemiological studies on eating disorders there are some methodological issues. Eating disorders are relatively rare among the general population and patients tend to deny or conceal their illnesses and avoid professional help [14], making community studies costly and ineffective. Therefore, many epidemiological studies use psychiatric case registers or medical records from hospitals in a circumscribed area as we have done in this research. This type of study will underestimate the occurrence of eating disorders in the general population, because not all patients will be detected, but will include the most serious cases that are the ones with higher morbidity and mortality in addition to those that will consume more health resources [15]. A large part of the advances in eating disorders treatment have to be focused on this group, during and after hospitalization, so it is necessary to know their characteristics well.

The Conjunto Mínimo Básico de Datos (translated as "basic minimum data set" and hereinafter referred to as CMBD), is the broadest administrative clinical database in Spain. Its completion is mandatory in the public hospitals of the Autonomous Communities that make up our National Health System [16]. Its sample size is huge, and we can say that its analysis would fit into the investigation of the so-called big data. The main advantage is its large sample size, which gives it a very adequate statistical power [17]. The main objective of this study is the statistical exploitation of the Minimum Basic Data Set of Castilla y León to provide epidemiological and clinical information (average age, gender, rural or urban background) and reference parameters on the casuistry and operation of hospitals (diagnosis and average stay), and to compare the trends of hospitalization due to eating disorders with the rest of mental disorders. With $94,223 \mathrm{~km}^{2}$, Castilla y León is the largest region in Europe. It has a population of around 2.5 million (2,410,819 inhabitants in 2018) [18], which are distributed in a balanced way between rural and urban areas, and within the latter in large, medium and small cities. It also presents a territorially unbalanced productive structure and economic development. This diversity places Castilla y Leon in a unique context in Spain and Europe for conducting epidemiological studies.

The study of trends in incidence plays a central role in epidemiology and public health [19]. However, only few studies analyze the rates of psychiatric hospitalization during childhood and adolescence; they may help interpret the effectiveness of actual treatments against these disorders and be a model of evaluation of further initiatives. On the other hand, administrative databases, such as hospital admissions have proved useful in obtaining epidemiological information of different processes, in the absence of specific records [20]. The objective is to know, as a method of evaluating the impact of preventive and therapeutic interventions in health, if there are changes in trends in hospitalization rates for eating disorders.

\section{Experimental Section}

We conducted a cross-sectional study of the hospital discharge database of Castilla y León from 2005 to 2015, selecting patients under 18 years old with a psychiatric diagnosis at discharge. Trends in the rates of hospitalization/1000 hospitalizations per year were studied by joinpoint regression analysis.

Sample: the data come from the CMBD and contain very valuable information to know the health reality of a population, since in addition to collecting the usual demographic data (age, sex, urban or rural residence), the CMBD records the diagnosis that has motivated the admission (main diagnosis). Finally, the CMBD includes the patient's date of admission and discharge, as well as their circumstance of admission (urgent, scheduled) and circumstance of discharge (discharge to his home, death, transfer 
to another hospital, etc.) [16]. The coding in the CMBD is done based on hospital discharge reports and, since they correlate closely with hospital admission, we will use both terms as synonyms in our work. The target population in the middle of the study period (2010) is made up of 370,762 children under 18 out of a total population of 2,547,408 people. For the standardization by age, the European standard population of 2013 was used.

The study population is made up of 1551 cases of hospital discharges with a main diagnosis of mental disorder, in children and adolescents (under 18), in the public hospitals of Sanidad de Castillay León (SACYL) and between 2005 and 2015, both inclusive. They were classified based on the criteria of the CMBD base of the hospital and the ICD-9-MC.

Variables analyzed: study of hospital discharges from hospitals in Castilla y León between 2005 and 2015. Patients with a primary diagnosis were selected upon discharge from abuse or dependence on psychoactive substances. Main diagnoses for hospital discharges according to selection of ICD-9-MC codes were used in previous research [21,22]. Codes used are detailed in Table 1.

Table 1. Main diagnoses for hospital discharges and associated ICD-9-MC codes.

\begin{tabular}{ccc}
\hline No. & Diagnosis Group & ICD-9 \\
\hline I & Psychosis (including depressive psychosis) & $295.00-295.99,297.00-297.99,298.00-298.99,299.00-299.99$ \\
II & Bipolar disorders & $296.00-296.19,296.40-296.81,296.89-296.99$ \\
III & Depressive (non-psychotic) disorders: & $296.20-296.39,296.82,300.40-300.59,301.10,309.00-309.19$, \\
IV & Anxiety disorders & $311.00-311.99$ \\
V & Adaptation disorders & $300.00-300.39,307.20-307.23,308.00-308.99,313.00-313.29$ \\
VI & Behavioral disorders & $309.20-309.99$ \\
VII & Substance abuse & $312.00-312.99$ \\
VIII & Eating disorders & $291.00-292.99,303.00-305.99$ \\
IX & Hyperactivity disorder & $307.10-307.19,307.50-307.59$ \\
X & Others & $314.00-314.99$ \\
& & $293.00-294.99,300.60-301.09,301.11-302.99,306.00-307.09$, \\
\end{tabular}

Statistical analysis: General descriptive data for the whole group and for each disease studied. Incidence rates are calculated per 1000 hospitalizations per year, global and specific, by type of substance and the trend over the 11 years studied, in general and by substance groups. The analysis of trends to determine if there were changes in the rates with significant statistical differences over time was performed by linear joinpoint regression, a test that assesses the trend over time in years for the series of selected patients. In this analysis, the points of change (joinpoints or inflection points) show statistically significant changes in the trend (ascending or descending). Graphically, the joinpoint models performed on the logarithm of the rate describe a sequence of connected segments. The point at which these segments come together is a joinpoint and represents a statistically significant change in the trend. In addition, for each segment, an annual change percentage was calculated for each trend by means of generalized linear models, assuming a Poisson distribution and showing in each case its level of associated statistical significance, with 95\% confidence intervals (95\% CI), and hospitalization rates stratified by gender with their respective $95 \% \mathrm{CI}$ and their statistical significance.

Software: we used free access software from the Research and Surveillance Program of the National Cancer Institute of the United States [23,24]. Values of $p<0.05$ were considered statistically significant differences. The statistical analysis was carried out with the SPSS v21.0 program.

The data that support the findings of this research are available at the Dirección General de Sistemas de Información, Calidad y Prestación Farmacéutica, located at: Pseo. de Zorrilla, 1. C.P.: 47007 Valladolid (Spain). Legal restrictions apply to access this data (Ley 16/2003, de 28 de mayo, de cohesión y calidad del Sistema Nacional de Salud), which were used with the relevant authorization in this study. We provide a link to the access conditions https:/www.boe.es/eli/es/1/2003/05/28/16. 


\section{Results}

The hospital network of Castilla y León comprises 14 centers: 3 regional, 6 provincial and 5 reference centers, structured on their health area and the availability of different medical specialties.

The CMBD of hospital discharges from Castilla y León, between 2001 and 2015, consists of $3,359,572$ records, of which 340,443 were under 18 years old. A total of 52,692 were hospitalizations in psychiatry units (of any age). Finally, 1551 of these correspond to patients under 18 admitted to the psychiatric units of the public centers in Castilla y León. The diseases were selected according to the indicated codes and between 2005 and 2015. The main diagnosis was eating disorders with 371 of 1551 hospitalizations followed by psychosis (257) and behavioral disorders (163). A total of 52,692 hospitalizations for any psychiatric diagnosis were used for calculating the rates (Tables 2 and 3).

Table 2. Annual population distribution, number of total hospital discharges by psychiatric cause as well as hospital discharge rate per 100,000 inhabitants and year adjusted by age.

\begin{tabular}{ccccc}
\hline Year & $\begin{array}{c}\text { Population of Castilla y } \\
\text { León (under 18 } \\
\text { Years Old) }\end{array}$ & $\begin{array}{c}\text { Total Child } \\
\text { Discharges } \\
\text { (n) }\end{array}$ & $\begin{array}{c}\text { Psychiatric } \\
\text { Discharges (under } \\
\text { 18 Years Old) }\end{array}$ & $\begin{array}{c}\text { Annual Rate } \\
\text { (Discharges by Psychiatric Pathology in } \\
\text { Children under 18/100,000) }\end{array}$ \\
\hline 2005 & 361,237 & 23,208 & 99 & 27.7 \\
2006 & 361,145 & 24,015 & 92 & 25.8 \\
2007 & 363,298 & 24,517 & 136 & 38.1 \\
2008 & 367,478 & 23,083 & 170 & 45.6 \\
2009 & 370,396 & 22,549 & 140 & 39.2 \\
2010 & 370,762 & 22,583 & 132 & 36.9 \\
2011 & 370,362 & 22,381 & 135 & 4.8 \\
2012 & 369,460 & 21,016 & 154 & 43.2 \\
2013 & 367,697 & 21,443 & 145 & 40.7 \\
2014 & 364,334 & 20,884 & 170 & 47.6 \\
2015 & 358,788 & 20,842 & 178 & 49.8 \\
\hline
\end{tabular}

Table 3. Hospitalization rates for the different processes studied per 100,000 inhabitants and year adjusted for age.

\begin{tabular}{|c|c|c|c|c|c|c|c|c|c|c|}
\hline Year & Psychosis & $\begin{array}{c}\text { Bipolar } \\
\text { Disorder }\end{array}$ & $\begin{array}{l}\text { Depressive } \\
\text { Disorders }\end{array}$ & $\begin{array}{c}\text { Anxiety } \\
\text { Disorders }\end{array}$ & $\begin{array}{l}\text { Adaptive } \\
\text { Disorders }\end{array}$ & $\begin{array}{l}\text { Behavioral } \\
\text { Disorders }\end{array}$ & $\begin{array}{l}\text { Substance } \\
\text { Abuse }\end{array}$ & $\begin{array}{c}\text { Eating } \\
\text { Disorders }\end{array}$ & $\begin{array}{c}\text { Hyperactive } \\
\text { Disorders }\end{array}$ & Others \\
\hline 2005 & 5 & 0 & 2.2 & 3 & 3.6 & 2.5 & 0.8 & 7.6 & 0.3 & 2.5 \\
\hline 2006 & 4.8 & 0.3 & 2.5 & 1.4 & 2 & 4.2 & 1.1 & 5.6 & 1.7 & 2.2 \\
\hline 2007 & 5.6 & 1.4 & 2 & 2.5 & 3.4 & 5.6 & 1.4 & 8.2 & 4.7 & 3.3 \\
\hline 2008 & 8.4 & 1.7 & 2.5 & 5.6 & 2.8 & 6.7 & 0.3 & 9 & 5.6 & 5 \\
\hline 2009 & 7.3 & 1.4 & 1.1 & 4.8 & 3.9 & 3.9 & 1.7 & 5.6 & 4.5 & 5 \\
\hline 2010 & 7 & 0.6 & 1.4 & 2.2 & 5.9 & 3.9 & 1.1 & 9 & 3.4 & 2.5 \\
\hline 2011 & 6.7 & 1.1 & 2 & 2 & 3.9 & 3.1 & 1.7 & 7.9 & 4.7 & 4.8 \\
\hline 2012 & 6.2 & 2.2 & 2 & 3.4 & 3.9 & 5 & 1.4 & 13.2 & 4 & 2 \\
\hline 2013 & 7.3 & 2 & 2.5 & 2.2 & 3.9 & 2.5 & 0.8 & 12.1 & 4.2 & 3.1 \\
\hline 2014 & 5.9 & 2.5 & 3.7 & 3.4 & 7.3 & 2.2 & 0.3 & 12.6 & 5.9 & 3.9 \\
\hline 2015 & 7.8 & 2.5 & 2.2 & 3.1 & 2.5 & 5.9 & 2.5 & 13.5 & 5 & 4.8 \\
\hline
\end{tabular}

In this sample, $49.8 \%$ were male versus $50.2 \%$ female. This proportion with respect to sex is similar in the rest of diagnosis groups except for psychosis, hyperactivity and bipolar disorders, which were predominant in men $(77.8 \%, 76.4 \%$ and $67.9 \%$ respectively). In the case of eating disorders, the percentage of women $81.9 \%$ was the highest of all groups.

The mean age of the total sample was $14.4 \pm 2.6$ years, with a range between $16 \pm 2.5$ years of average age of the substance abuse group and $12.6 \pm 3$ years of average age of hyperactivity group. The urban or rural origin remains fairly stable for all groups in an approximate ratio of 7:3 except for the bipolar disorder that approaches parity ( $58.2 \%$ vs. $41.8 \%)$ (Table 4$)$. 
Table 4. Characteristics of the cases analyzed, such as psychiatric pathology in general and for each of the processes studied.

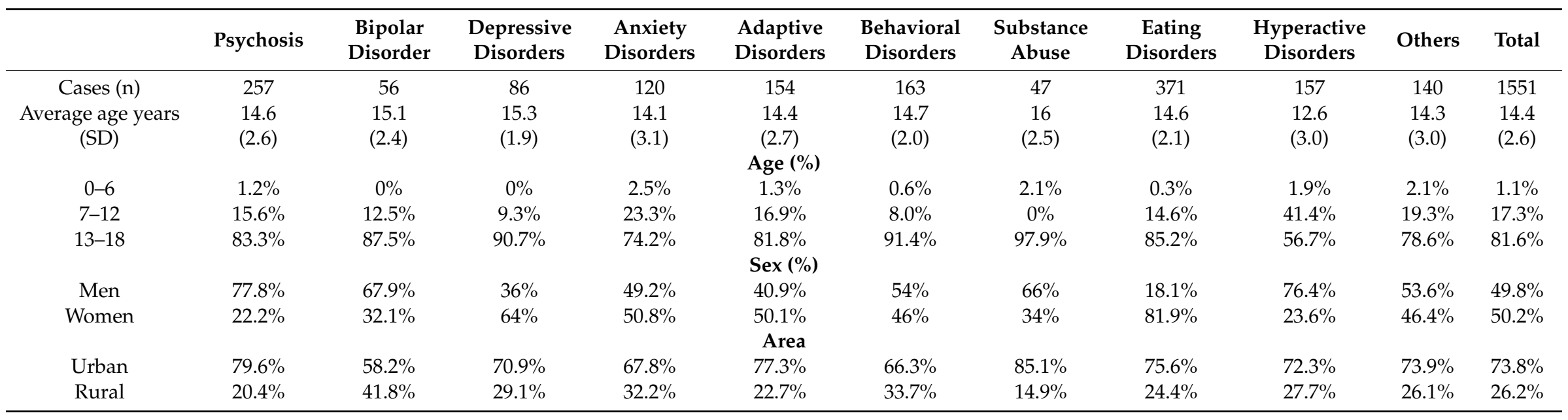

Table 5. Average stay in days per process studied and total number of days of accumulated stay per process.

\begin{tabular}{|c|c|c|c|c|c|c|c|c|c|c|c|}
\hline & Psychosis & $\begin{array}{l}\text { Bipolar } \\
\text { Disorder }\end{array}$ & $\begin{array}{l}\text { Depressive } \\
\text { Disorders }\end{array}$ & $\begin{array}{c}\text { Anxiety } \\
\text { Disorders }\end{array}$ & $\begin{array}{l}\text { Adaptive } \\
\text { Disorders }\end{array}$ & $\begin{array}{c}\text { Behavioral } \\
\text { Disorders }\end{array}$ & $\begin{array}{l}\text { Substance } \\
\text { Abuse }\end{array}$ & $\begin{array}{c}\text { Eating } \\
\text { Disorders }\end{array}$ & $\begin{array}{l}\text { Hyperactive } \\
\text { Disorders }\end{array}$ & Others & Total \\
\hline $\begin{array}{l}\text { Average stay days } \\
\text { (DE) }\end{array}$ & $\begin{array}{c}19.6 \\
(28.5)\end{array}$ & $\begin{array}{c}19.8 \\
(12.3)\end{array}$ & $\begin{array}{c}14.5 \\
(13.9)\end{array}$ & $\begin{array}{c}14.7 \\
(13.5)\end{array}$ & $\begin{array}{l}12.6 \\
(9.0)\end{array}$ & $\begin{array}{c}8.9 \\
(9.2)\end{array}$ & $\begin{array}{l}11.2 \\
(8.2)\end{array}$ & $\begin{array}{c}29.2 \\
(21.8)\end{array}$ & $\begin{array}{c}18.4 \\
(15.5)\end{array}$ & $\begin{array}{c}13.8 \\
(18.2)\end{array}$ & $\begin{array}{c}18.5 \\
(19.9)\end{array}$ \\
\hline
\end{tabular}


Analysis of Hospitalization Rate Trends

- Bipolar Disorders Trend Changed in 2007, with Two Upward Trends in 2005-2007 and 2007-2015.

- Hyperactivity disorders showed two upward trends in 2005-2007 and 2007-2015 with a joinpoint in 2007.

- Other groups

(1) For psychosis, depressive disorders, adaptive disorders, substance abuse and other disorders, slightly ascending—although statistically non-significant—-trends were observed.

(2) For anxiety disorders and behavioral disorders groups, a slight downward trend was observed although without statistical significance.

- Eating disorders was the only group that presented an upward and continuous trend throughout the study period. This statistically significant increase showed an annual percentage of change of $7.8 \%$ (Figure 1).

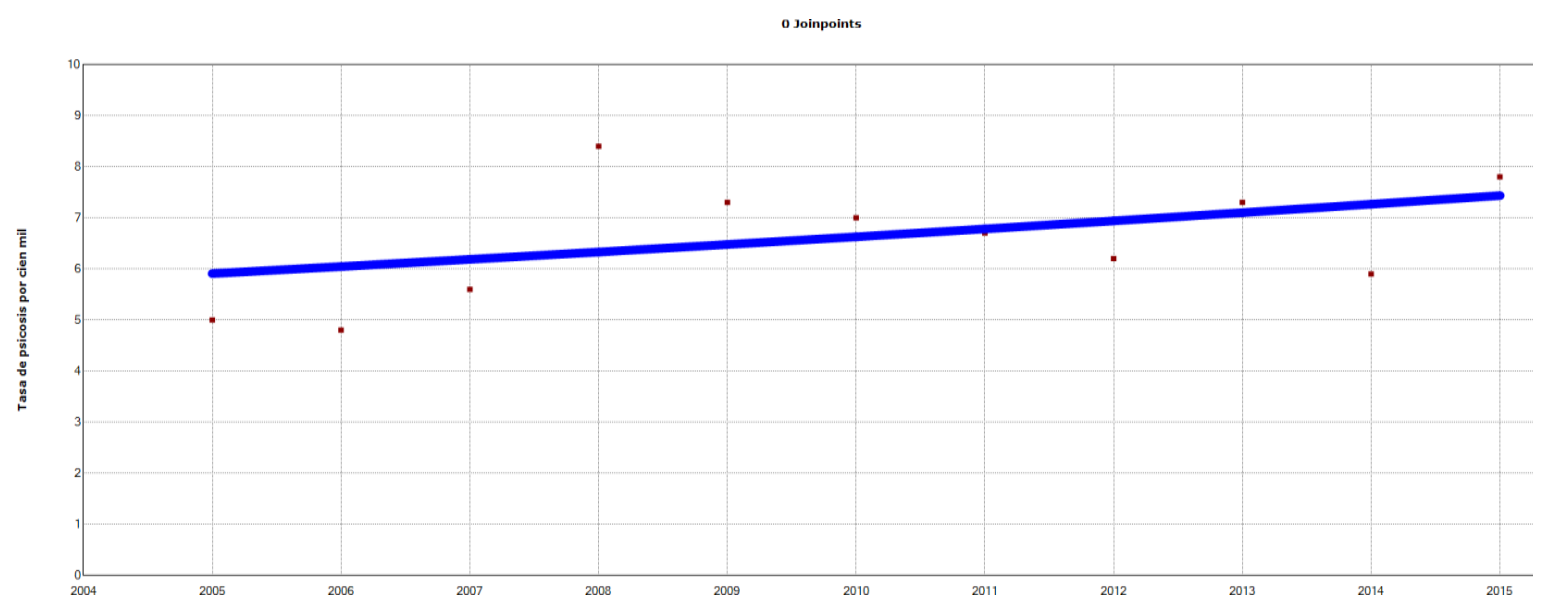

(A)

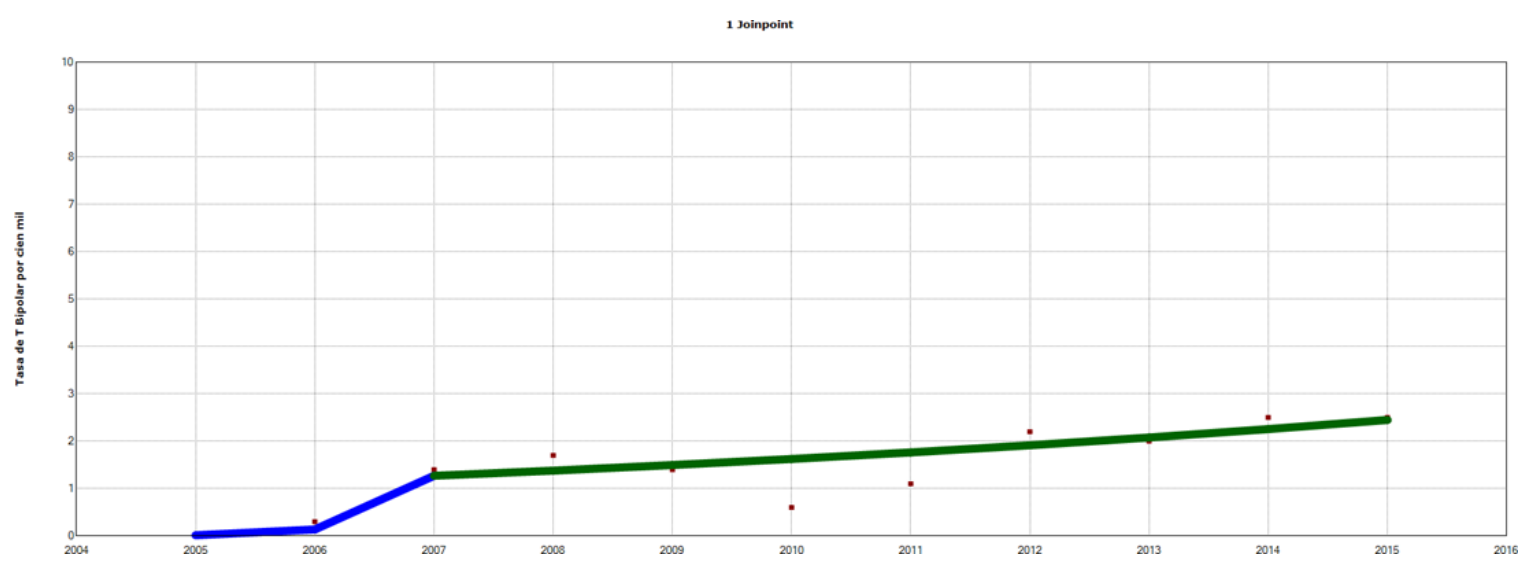

(B)

Figure 1. Cont. 


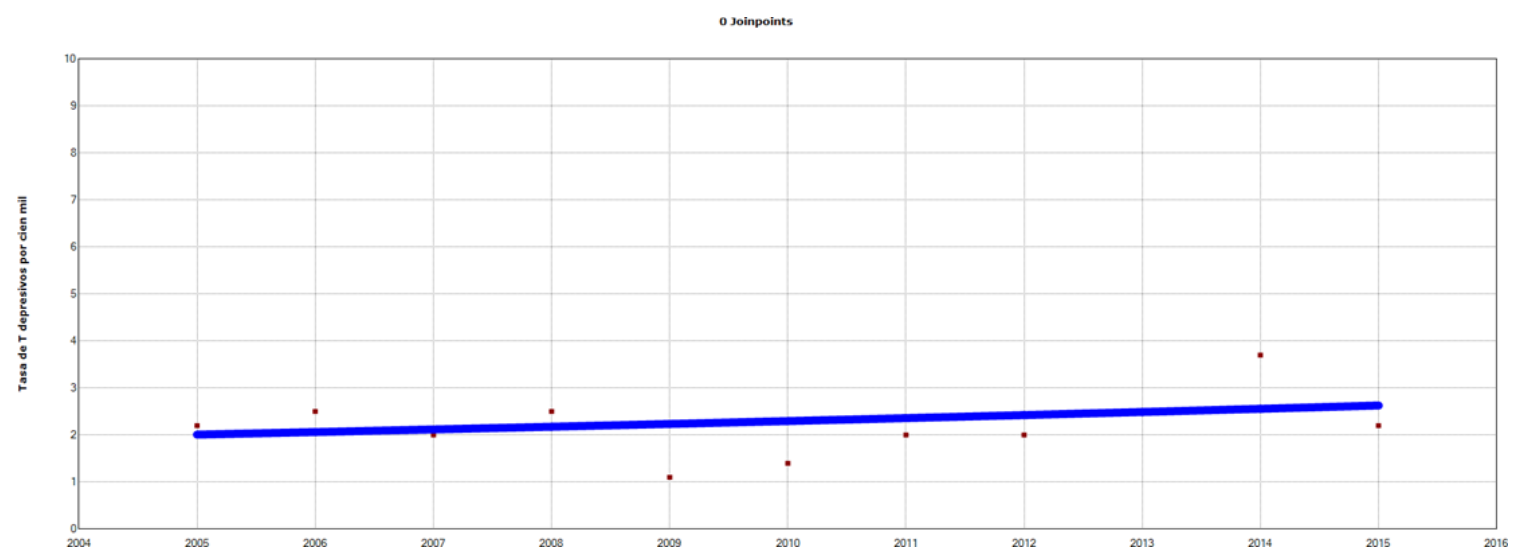

(C)

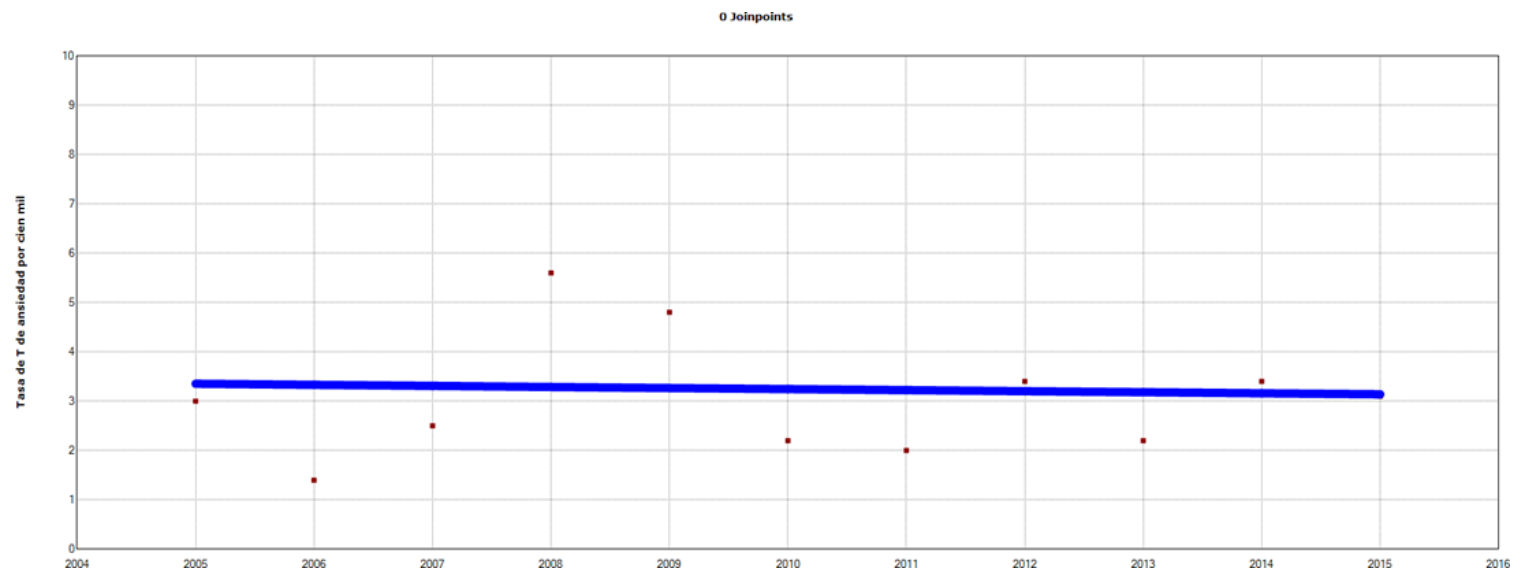

(D)

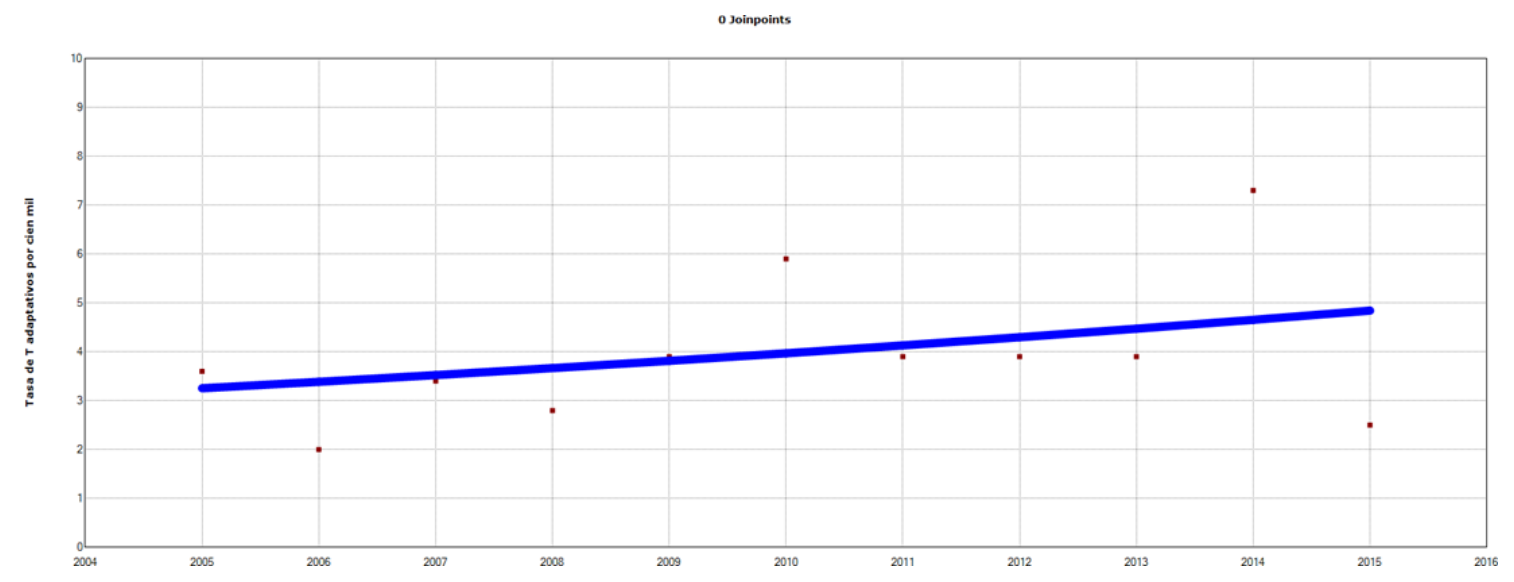

(E)

Figure 1. Cont. 


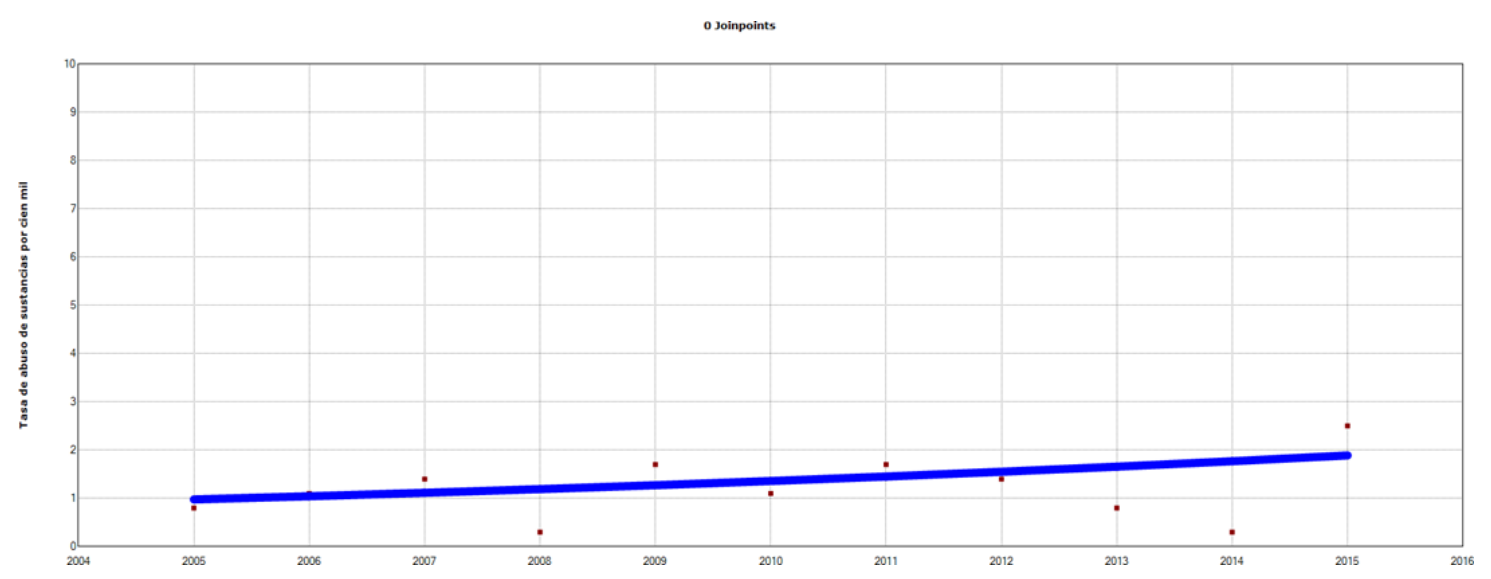

(F)

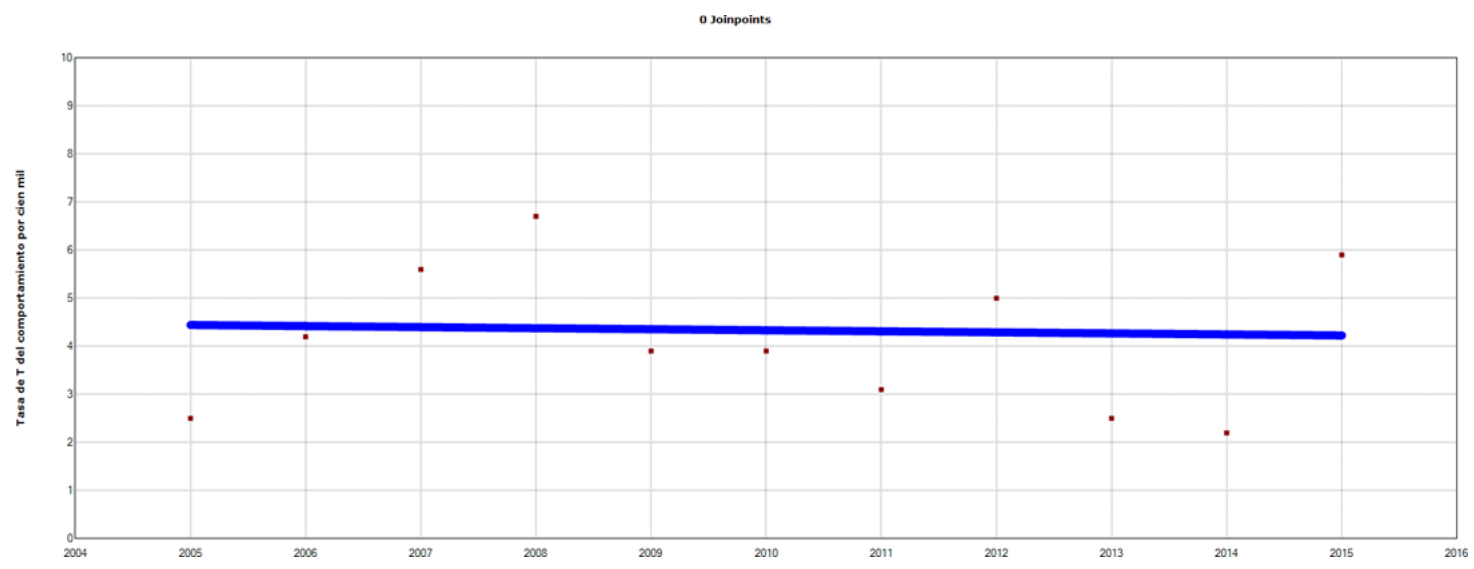

(G)

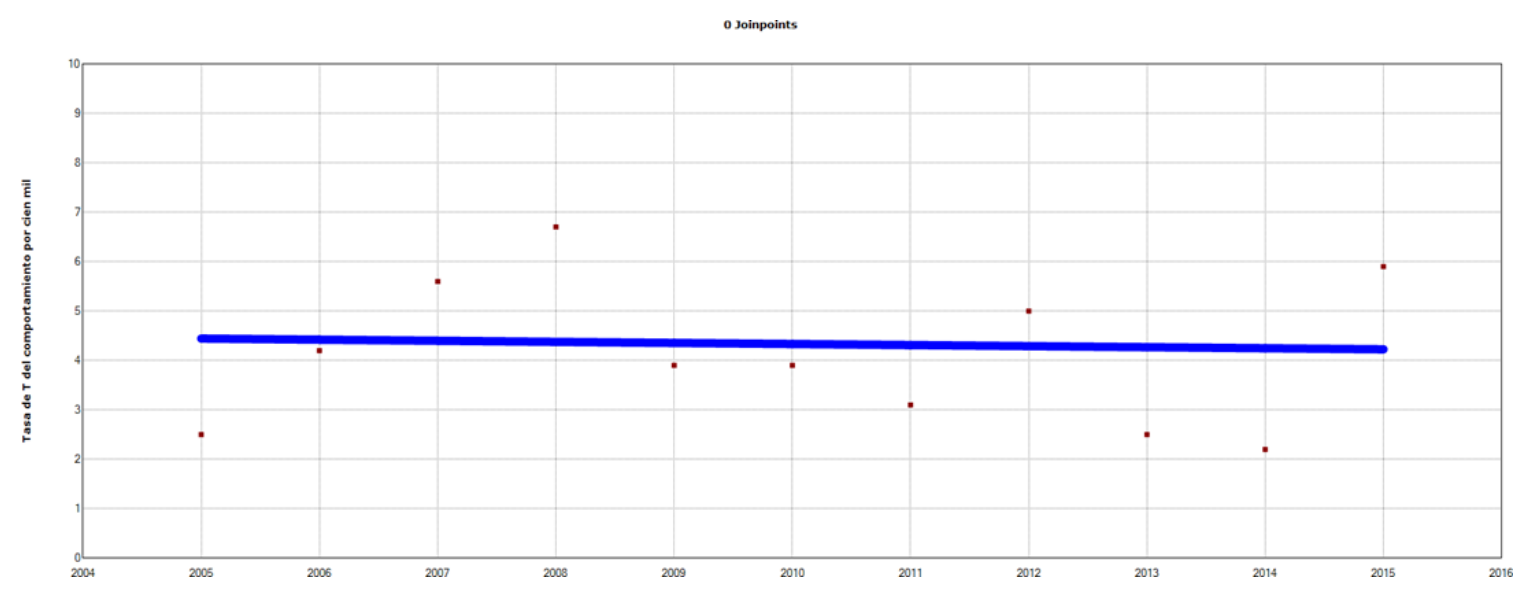

(H)

Figure 1. Cont. 


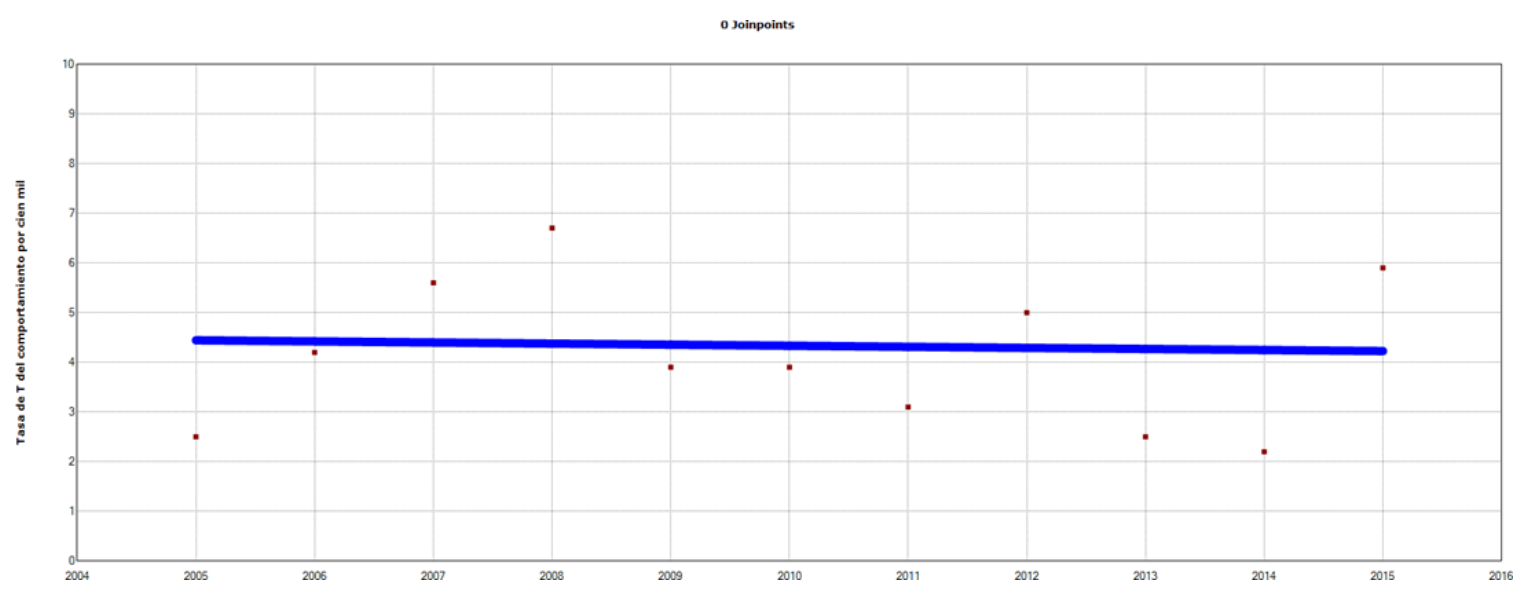

(I)

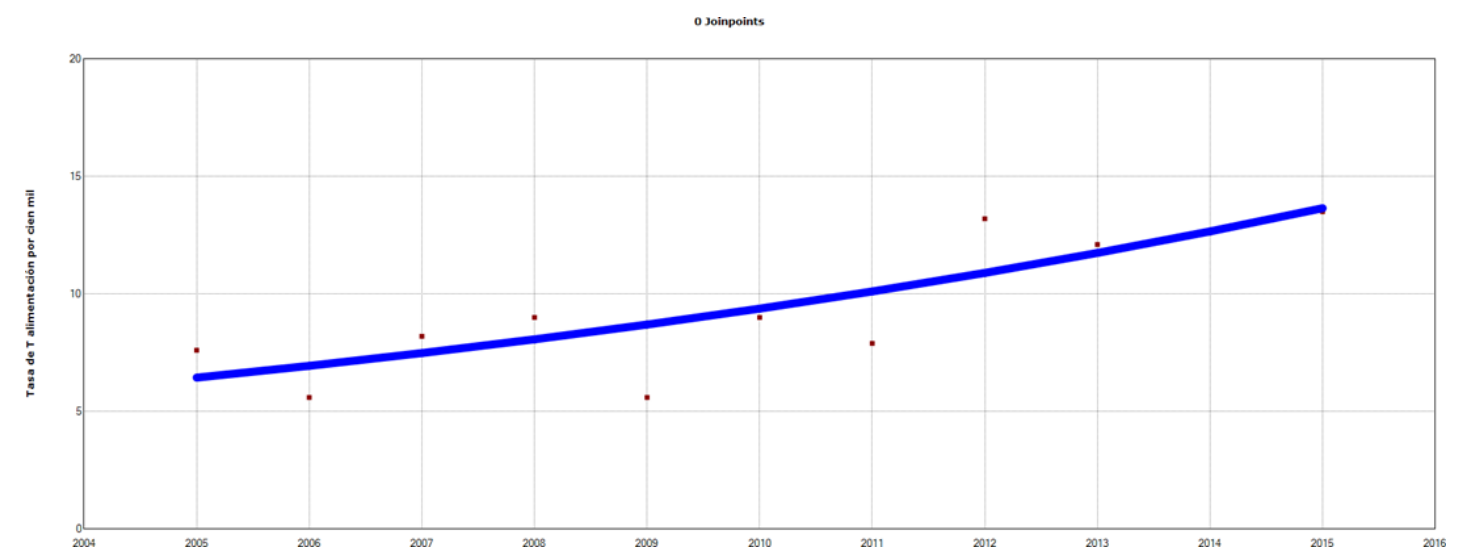

(J)

Figure 1. Hospitalization rates per 100,000 inhabitants. Analysis by groups of the diseases studied (A-J, from left to right and from top to bottom) with inflection points (joinpoints) and APC. (A) Psychosis: 0 joinpoints, APC 2005-2015 2.3 (95\% CI -1.4 to 6.2, $p<0.05 *$ ). (B) Bipolar Disorder, 1 joinpoint (2007) APC 2005-2007 827 (95\% CI -32.4 to 12,591, $p=0.1$ ), APC 2007-2015 8.5 (95\% CI -2.7 to 21.1, $p=0.1$ ). (C) Depressive disorders, 0 joinpoints, APC 2005-2015 2.7 (95\% CI -3.3 to 9.1, $p=0.3$ ). (D) Anxiety disorders, 0 joinpoints, APC 2005-2015 -0.7 (95\% CI -9.2 to 8.7, $p=0.9)$. (E) Adaptative disorders, 0 joinpoints, APC 2005-2015 4.1 (95\% CI -3.8 to 12.5, $p=0.3$ ). (F) Behavioral disorders, 0 joinpoints, 2005-2015 -0.5 (95\% CI -8.4 to 8.1, $p=0.9$ ). (G) Substance use disorders, 0 joinpoints, APC 2005-2015 6.8 (95\% CI -3.4 to 18, $p=0.2)$. (H) Hyperactivity disorders, 1 joinpoint (2007) APC 2005-2007 215 (95\% CI -56.8 to 2200, $p=0.2$ ), APC 2007-2015 0.6 (95\% CI -6.0 to $7.7, p=0.8$ ), (I) others, 0 joinpoints, APC 2005-2015 2.8 (95\% CI -4.4 to10.5). (J) Eating disorders: 0 joinpoints, APC 2005-2015 7.8 (95\% CI 3.8 to $\left.12, p<0.05^{*}\right)$. APC: annual percentage change; $95 \%$ CI: $95 \%$ confidence interval. $\left(^{*}\right)$ : APC statistically significant. Red dots: exact annual value. Lines represent trends, with line colors changing where joinpoints were identified. A blue line only represents a monotonic trend. X-axis: years (from 2004 to 2016). Y-axis: discharge rate for each drug studied; discharge rates for drugs/1000 hospital discharges. APC: annual percentage of change. 95\% CI: 95\% confidence interval. Data represent exact annual value. * Statistically significant CAP.

\section{Discussion}

This study provides three novel aspects scarcely published in our area. First of all, there is the use of a database, such as the CMBD for hospital discharges, whose analysis transforms data into useful 
information for health decision-making both in the context of the years analyzed and in the present, as very little similar research has been published so far [25]. Secondly, this this type of cross-association study is common in epidemiological research and is more than a mere description, within a context of clinical reality such as the discharge of a hospital network. And finally, the statistical methodology used, using joinpoint regression models, is very effective to identify trends and changes in different pathologies over time. The results of the research showed that hospitalization rates remained stable in the 11 years of research for most of the pathologies. The average stay is similar to that reported by other studies although with notable differences between diagnostic groups, with eating disorders [9].

Another remarkable fact is the continuous increasing trend that occurs along 11 years of research with an annual increase of $7.8 \%$ for eating disorders. They had the greatest impact on resource consumption with the highest number of discharges (371) and one of the highest average stays $(29.2 \pm 21.8)$ (Table 5), according to previous evidence [26]. Our hypotheses are that we face a kind of second wave of improvement in the psychiatric assistance of children and adolescents after a long period in which the main classic psychiatric disorders such as schizophrenia, depression or bipolar disorder have been prioritized, that supply has generated demand or, most likely, a primary increase in the prevalence of eating disorders.

The high proportion of hospitalizations ( $85.2 \%$ between $13-18$ years old) that take place in the age group near the age of majority (18 in Spain) reveals the importance of maintaining care continuity [27] (e.g., with specialized units or programs) during the transfer to adult mental health care, as many psychiatry departments have separate teams of child and adult psychiatry [28].

Health managers have tended to traditional approaches, accustomed to functioning independently and relying on their own clinical judgement, sometimes by imitation or by previous operation, and seldom depending on protocols based on big data. This, together with an under-investment in information technology, results in the use of older information systems, with limited ability in standardizing and consolidating data. The current legal restrictions for privacy concerns do not make data sharing easy either. The Spanish healthcare system face unprecedented challenges. Cost pressures have driven health managers to embrace evidence-based medicine. The treatment of ED should be based on a multimodal model [29], which should require knowledge of ED epidemiology, and the planning of ED services should adapt to the characteristics of the local catchment area [30] in order to ensure this heterogeneous clinical population the most appropriate treatment options, rooted in their real clinical history and course.

Limitations: As limitations of the study, it could be considered that the data were obtained retrospectively from a non-specifically clinical administrative record, whose coding could have undergone changes over the years and in the different hospitals. Despite this, the study of databases such as the CMBD, with a large volume of information, is a recognized approach to the knowledge of the reality of a pathology. Dieting behaviors and body image concerns are common in adolescence and it can be challenging to identify those patients at the extreme end of this spectrum who develop an eating disorder. That is why they may be underdiagnosed and hospitalization samples like this guarantee established diagnoses and in cases of severity.

\section{Conclusions}

A total of 53,748 hospital discharges due to psychiatric diseases took place during the research period, and 1551 of those corresponded to patients under 18; $2.9 \%$ of the total. Hospitalizations due to eating disorders are the most frequent and long, growing by $7.8 \%$ at least until 2015. The innovative statistical methodology of joinpoint regression models may be very useful in identifying trends and changes in different pathologies over time, reducing costs and improving patient outcomes.

Author Contributions: Conceptualization, C.L.-Á., J.M.A.-d.L. and A.I.Á.-N.; methodology, C.L.-Á. and J.M.A.-d.L.; software, J.M.A.-d.L.; validation, A.I.Á.-N., C.R. and M.A.F.-M.; formal analysis, J.M.A.-d.L.; investigation, C.L.-Á.; resources, C.R. and M.A.F.-M.; data curation, C.R., J.M.A.-d.L. and M.A.F.-M.; 
writing—original draft preparation, C.L.-Á.; writing—review and editing, A.I.Á.-N. and M.T.P.-H.; supervision, C.L.-Á. and J.M.A.-d.L.; project administration, C.L.-Á. and A.I.Á.-N.

Funding: This research received no external funding.

Acknowledgments: We would like to express our sincere gratitude to the Dirección General de Información, Calidad y Prestación Farmacéutica of the Gerencia Regional de Salud de Castilla y León for providing the data of the CMBD.

Conflicts of Interest: The authors declare no conflict of interest for this research.

\section{References}

1. Ravens-Sieberer, U.; as the BELLA study group; Wille, N.; Erhart, M.; Bettge, S.; Wittchen, H.-U.; Rothenberger, A.; Herpertz-Dahlmann, B.; Resch, F.; Hölling, H.; et al. Prevalence of mental health problems among children and adolescents in Germany: Results of the BELLA study within the National Health Interview and Examination Survey. Eur. Child Adolesc. Psychiatry 2008, 17, 22-33. [CrossRef] [PubMed]

2. Merikangas, K.R.; He, J.; Brody, D.; Fisher, P.W.; Bourdon, K.; Koretz, D.S. Prevalence and treatment of mental disorders among US children in the 2001-2004 NHANES-PubMed-NCBI. Available online: https://pubmed.publicaciones.saludcastillayleon.es/pubmed/20008426 (accessed on 15 February 2018).

3. Kessler, R.C.; Avenevoli, S.; Costello, J.; Green, J.G.; Gruber, M.J.; McLaughlin, K.A.; Petukhova, M.; Sampson, N.A.; Zaslavsky, A.M.; Merikangas, K.R. Severity of 12-month DSM-IV disorders in the National Comorbidity Survey Replication Adolescent Supplement. Arch. Gen. Psychiatry 2012, 69, 381-389. [PubMed]

4. Barkmann, C.; Schulte-Markwort, M. Prevalence of emotional and behavioral disorders in children and adolescents in Germany-A systematic literature review. Psychiatr. Prax. 2004, 31, 278-287. [CrossRef] [PubMed]

5. Litmanen, J.; Fröjd, S.; Marttunen, M.; Isomaa, R.; Kaltiala-Heino, R. Are eating disorders and their symptoms increasing in prevalence among adolescent population? Nord. J. Psychiatry 2017, 71, 61-66. [CrossRef]

6. Swanson, S.A.; Crow, S.J.; Le Grange, D.; Swendsen, J.; Merikangas, K.R. Prevalence and correlates of eating disorders in adolescents. Results from the national comorbidity survey replication adolescent supplement. Arch. Gen. Psychiatry 2011, 68, 714-723. [CrossRef]

7. Gathright, M.M.; Holmes, K.J.; Morris, E.M.; Gatlin, D.A. An Innovative, Interdisciplinary Model of Care for Inpatient Child Psychiatry: An Overview. J. Behav. Health Serv. Res. 2016, 43, 648-660. [CrossRef]

8. Peebles, R.; Lesser, A.; Park, C.C.; Heckert, K.; Timko, C.A.; Lantzouni, E.; Liebman, R.; Weaver, L. Outcomes of an inpatient medical nutritional rehabilitation protocol in children and adolescents with eating disorders. J. Eat. Disord. 2017, 5, 7. [CrossRef]

9. Shafer, A. Inpatient Psychiatric Hospitalization in Texas 1999 to 2010. TexMed 2019, 1, 115.

10. Boege, I.; Corpus, N.; Schepker, R.; Kilian, R.; Fegert, J.M. Cost-effectiveness of intensive home treatment enhanced by inpatient treatment elements in child and adolescent psychiatry in Germany: A randomised trial. Eur. Psychiatry 2015, 1, 583-589. [CrossRef]

11. Derenne, J. The Role of Higher Levels of Care for Eating Disorders in Youth. Child Adolesc. Psychiatr. Clin. N. Am. 2019, 28, 573-582. [CrossRef]

12. Baxter, A.J.; Patton, G.; Scott, K.M.; Degenhardt, L.; Whiteford, H.A. Global epidemiology of mental disorders: What are we missing? PLoS ONE 2013, 8, e65514. [CrossRef]

13. Erskine, H.E.; Baxter, A.J.; Patton, G.; Moffitt, T.E.; Patel, V.; Whiteford, H.A.; Scott, J.G. The global coverage of prevalence data for mental disorders in children and adolescents. Epidemiol. Psychiatr. Sci. 2017, 26, 395-402. [CrossRef] [PubMed]

14. Musolino, C.; Warin, M.; Wade, T.; Gilchrist, P. 'Healthy anorexia': The complexity of care in disordered eating. Soc. Sci. Med. 2015, 139, 18-25. [CrossRef]

15. Doran, C.M.; Kinchin, I. A review of the economic impact of mental illness. Aust. Health Rev. Publ. Aust. Hosp. Assoc. 2019, 43, 43-48. [CrossRef] [PubMed]

16. Meléndez Frigola, C.; Arroyo Borrell, E.; Saez, M. Data Analysis of Subacute Patients with Registered Information in the Minimum Basic Data Set for Social-Healthcare (CMBD-RSS), Spain. Rev. Esp. Salud. Publica 2016, 90, e1-e7. [PubMed] 
17. Button, K.S.; Ioannidis, J.P.A.; Mokrysz, C.; Nosek, B.A.; Flint, J.; Robinson, E.S.J.; Munafò, M.R. Power failure: Why small sample size undermines the reliability of neuroscience. Nat. Rev. Neurosci. 2013, 14, 365-376. [CrossRef]

18. Cifras Oficiales de Población | Estadística | Junta de Castilla y León. Available online: https://estadistica.jcyl. es/web/jcyl/Estadistica/es/Plantilla100/1284300554709/_/__ (accessed on 28 May 2019).

19. Olsen, H.E.; Ikeda, C.T.; Echko, M.M.; Ballestreros, K.E.; Manguerra, H.; Martopullo, I.; Millear, A.; Shields, C.; Smith, A.; Strub, B.; et al. Diseases, Injuries, and Risk Factors in Child and Adolescent Health, 1990 to 2017: Findings From the Global Burden of Diseases, Injuries, and Risk Factors 2017 Study. JAMA Pediatr. 2019, 173, e190337.

20. Inzitari, M.; Espinosa Serralta, L.; Pérez Bocanegra, M.C.; Roquè Fíguls, M.; Argimón Pallàs, J.M.; Farré Calpe, J. Intermediate hospital care for subacute elderly patients as an alternative to prolonged acute hospitalization. Gac. Sanit. 2012, 26, 166-169. [CrossRef]

21. Boscarino, J.A.; Moorman, A.C.; Rupp, L.B.; Zhou, Y.; Lu, M.; Teshale, E.H.; Gordon, S.C.; Spradling, P.R.; Schmidt, M.A.; Trinacty, C.M.; et al. Comparison of ICD-9 Codes for Depression and Alcohol Misuse to Survey Instruments suggest these Codes should be used with Caution. Dig. Dis. Sci. 2017, 62, $2704-2712$. [CrossRef]

22. Gfroerer, J.C.; Adams, E.H.; Moien, M. Drug abuse discharges from non-federal short-stay hospitals. Am. J. Public Health 1988, 78, 1559-1562. [CrossRef]

23. Kim, H.J.; Fay, M.P.; Feuer, E.J.; Midthune, D.N. Permutation tests for joinpoint regression with applications to cancer rates. Stat. Med. 2000, 19, 335-351. [CrossRef]

24. Joinpoint Trend Analysis Software Provided by US National Cancer Institute. Surveillance Research Program. Available online: http://surveillance.cancer.gov/joinpoint/ (accessed on 16 March 2017).

25. Miquel, L.; Rehm, J.; Shield, K.D.; Vela, E.; Bustins, M.; Segura, L.; Colom, J.; Anderson, P.; Gual, A. Alcohol, tobacco and health care costs: A population-wide cohort study $(\mathrm{n}=606947$ patients) of current drinkers based on medical and administrative health records from Catalonia. Eur. J. Public Health 2018, 28, 674-680. [CrossRef] [PubMed]

26. Morris, J.; Simpson, A.V.; Voy, S.J. Length of stay of inpatients with eating disorders. Clin. Psychol. Psychother. 2015, 22, 45-53. [CrossRef] [PubMed]

27. Current Issues in Transitioning from Pediatric to Adult-Based Care for Youth with Chronic Health Care Needs-PubMed-NCBI. Available online: https://www.ncbi.nlm.nih.gov/pubmed/26340879 (accessed on 17 October 2019).

28. Bonanno, M.; Ogez, D.; Bourque, C.J.; Laverdière, C.; Sultan, S. The Role of Pediatric Psychologists in the Transition of Youth to Adult Health Care: A Descriptive Qualitative Study of Their Practice and Recommendations. J. Clin. Psychol. Med. Settings 2019, 26, 353-363. [CrossRef]

29. Halmi, K.A. Anorexia nervosa: An increasing problem in children and adolescents. Dialogues Clin. Neurosci. 2009, 11, 100-103.

30. Wang, M.; Brunekreef, B.; Gehring, U.; Szpiro, A.; Hoek, G.; Beelen, R. A new technique for evaluating land use regression models and their impact on health effect estimates. Epidemiol. Camb. Mass. 2016, 27, 51-56. [CrossRef]

(C) 2019 by the authors. Licensee MDPI, Basel, Switzerland. This article is an open access article distributed under the terms and conditions of the Creative Commons Attribution (CC BY) license (http://creativecommons.org/licenses/by/4.0/). 